\title{
Parametric analysis of wheel wear in high-speed vehicles
}

\author{
$\mathrm{Na}$ Wu $\cdot$ Jing Zeng
}

Received: 9 December 2013/Revised: 29 April 2014/Accepted: 30 April 2014/Published online: 23 May 2014

(C) The Author(s) 2014. This article is published with open access at Springerlink.com

\begin{abstract}
In order to reduce the wheel profile wear of highspeed trains and extend the service life of wheels, a dynamic model for a high-speed vehicle was set up, in which the wheelset was regarded as flexible body, and the actual measured track irregularities and line conditions were considered. The wear depth of the wheel profile was calculated by the well-known Archard wear law. Through this model, the influence of the wheel profile, primary suspension stiffness, track gage, and rail cant on the wear of wheel profile were studied through multiple iterative calculations. Numerical simulation results show that the type XP55 wheel profile has the smallest cumulative wear depth, and the type LM wheel profile has the largest wear depth. To reduce the wear of the wheel profile, the equivalent conicity of the wheel should not be too large or too small. On the other hand, a small primary vertical stiffness, a track gage around 1,435-1,438 mm, and a rail cant around 1:35-1:40 are beneficial for dynamic performance improvement and wheel wear alleviation.
\end{abstract}

Keywords Parametric analysis - Wheel profile wear . Flexible wheelset $\cdot$ High-speed railway $\cdot$ Vehicle dynamic model Finite element method

\section{Introduction}

With the rapid development of high-speed railways, study on wheel profile wear has become increasingly important

\author{
N. Wu $(\bowtie) \cdot$ J. Zeng \\ State Key Laboratory of Traction Power, Southwest Jiaotong \\ University, Chengdu 610031, China \\ e-mail: wunapp@126.com \\ J. Zeng \\ e-mail: zeng@swjtu.edu.cn
}

$[1,2]$. Wheel and rail wear is a fundamental problem in railways; the change of profile shape affects the dynamic characteristics of railway vehicles such as stability and passenger comfort and, in the worst case, can cause derailment [3]. Therefore, it is very important to establish a reliable vehicle dynamic model and wheel/rail wear model to analyze the influence of vehicle parameters on the wear of the wheel profile. However, it is difficult to predict wheel and rail wear simultaneously using state-of-the-art numerical techniques [4]; so we focus on predicting the wear of railway wheels in this work.

To date, many papers on wheel/rail wear prediction have been published. The existing research work of wheel profile wear prediction mainly focus on three aspects: 1) to establish a prediction model based on the vehicle dynamics model, wheel-rail rolling contact model, and wheel material wear model; 2) to confirm the maximum limit value while updating wheel profiles; and 3) to analyze the influence of vehicle track parameters on the wear.

For the wheel profile wear prediction model and maximum limit value as the interval for the wheel profile updating in the repeated dynamic analysis of the vehicle, some scholars carried out studies in different ways. Fries et al. [5] compared four existing wear models, predicting the wear of a freight wagon wheel profile when travel ing in straight lines. The results showed that there was no significant difference between the four wear models. Pearce et al. [6] proposed a wear model for a simple wheel profile by calculating the global contact forces and creepage acting on the contact patch. The amount of material removed was calculated through a wear index (later called the "Derby wear index"), and the wear process was analyzed on a combined straight line and S-curve route. They established that a distance of $1,100 \mathrm{~km}$ could be traveled before the wear surface needed upgrading. Li et al. [7] 
adopted SIMPACK software to simulate vehicle dynamics. They analyzed the wheel-rail contact with the non-Hertzia multi-point and conformal contact model based on CONTACT, and the wear depth of $0.1 \mathrm{~mm}$ is considered as the interval for the wheel profile updating in the repeated dynamic analysis of the vehicle. Jendel et al. [8] developed total simulation conditions using discrete and grouped different curve radii, and analyzed the wheel-rail contact problem using the Hertz theory, Fastsim method, and the Archard model for wear calculations. The update of the wheel profile wear was established when the maximum wear value reached $0.1 \mathrm{~mm}$ or the operation distance reached 1,500 or $2,500 \mathrm{~km}$.

The wheel-rail wear is influenced by many factors, and governed by a complex mechanism. Some researchers addressed this problem by analyzing the effect of vehicle and track parameters on the wheel wear. Luo et al. [9] analyzed the influence of the vehicle parameters on the wheel profile wear with a frictional work model. Ignesti et al. [10] developed a mathematical model for wheel-rail wear evaluation in complex railway lines and compared the performance provided by different wheel profiles in terms of resistance to wear and running stability. Pombo [11] used a computational tool to simulate the dynamic performance of an integrated railway system and predict the wear evolution of wheel profiles, taking into account the influence of track condition. Agostinacchio et al. [12] evaluated the influence of the geometrical and mechanical parameters of the superstructure on the dynamic response of the railway. Fergusson et al. [13] presented an analysis of wheel wear as a function of the relationship between the lateral and longitudinal primary suspension stiffness and the coefficient of friction at the center plate between the wagon body and the bolster. Li et al. [14] studied the relationship between the rail cant and wheel-rail rolling contact behavior. The results showed that the rail cant had a great influence on the wheel-rail rolling contact behavior. Wang et al. [15] analyzed the rolling contact geometrical parameters and creepage of the JM3 wheelset and $60 \mathrm{~kg} / \mathrm{m}$ rail track in static rolling contact under different structural parameters of the track such as rail cant and rail gage. Chen et al. [16] simulated and analyzed the influence on wheel/ rail wear caused by vehicle speed, rail cant, super-elevation on curve, and rail lubrication.

Most of the above studies regarded wheel as a rigid body when carrying out the wheel wear prediction. However, when the vehicle passed through a small radius curve, the influence of wheel profiles on the wheel-rail normal force, the contact patch size, position of the contact point, adhesion area, and the distribution of the slide area were different for a flexible wheelset and a rigid wheelset. Chang et al. [17] studied the wheel-rail wear by establishing a three-dimensional dynamic finite element model.
Baeza et al. [18] built a model that coupled rotating flexible wheelset and a flexible track model for simulating vehicletrack interaction at high frequencies when investigating growth in rail roughness. Due to the increase of the vehicle speed and the presence of roughness, contact geometry perturbations induce a variation of forces in the vertical and tangential direction, and the torsional vibration of the wheelset axle may, therefore, be excited at high frequency. These vibrations directly affect the contact dynamic action of wheel/rail, and then influence on the wheel profile wear. Therefore, in the prediction of wheel profile wear, wheelset should be considered as flexible body.

In addition, when analyzing the impact of rail and vehicle parameters on wheel profile wear, the above studies completed the wheel profile wear prediction by a single iteration. However, wheel profile deformation caused by wear will change the tendency of these parameters' influence on the wheel profile wear. Therefore, when analyzing the influence of the rail and vehicle parameters on the wheel profile wear, wheel profile should be updated many times in calculation.

In the present work, in order to reduce wear of the wheel profile and extend the service life of wheels, a dynamic model for a high-speed vehicle was set up, in which the wheelset was regarded as flexible body, and the actual measured track irregularities and line conditions were considered. The wear depth of the wheel profile was calculated by the well-known Archard wear law [19]. Through this model, the influence of the wheel profile, primary suspension stiffness, track gage, and rail cant on the wear of the wheel profile were studied through multiple iterative calculations.

\section{Model descriptions}

\subsection{Vehicle dynamic model}

The rigid-flexible coupling dynamic model of a high-speed vehicle was established, and the vehicle system included a car-body, two bogie frames, four wheelsets, and eight axle boxes. To take into account the effect of wheel-rail highfrequency vibration on the wear, the wheelset was considered to be flexible, and the other bodies assumed to be rigid. The nonlinearities caused by wheel-rail interaction and suspension parameters were considered in the model. The vehicle system dynamic equations can be expressed in the following form:

$\boldsymbol{M} \ddot{\boldsymbol{x}}+\boldsymbol{F}(\boldsymbol{x}, \dot{\boldsymbol{x}})=\boldsymbol{P}(\boldsymbol{x}, \dot{\boldsymbol{x}}, t)$,

where $\boldsymbol{x}$ denotes the displacement vector, $\boldsymbol{M}$ indicates the system mass matrix, $\boldsymbol{F}$ is the nonlinear suspension forces, and $\boldsymbol{P}$ is an item related to the nonlinear wheel/rail forces and track inputs. 
The wheelset finite element model was set up using ANSYS software, in which one axle, two wheels, and three brake discs were included. The eight-node hexahedral 3D solid element mesh division was adopted for the modeling, and the whole unit had 70,592 elements with 83,616 nodes. The wheelset finite element model is shown in Fig. 1.

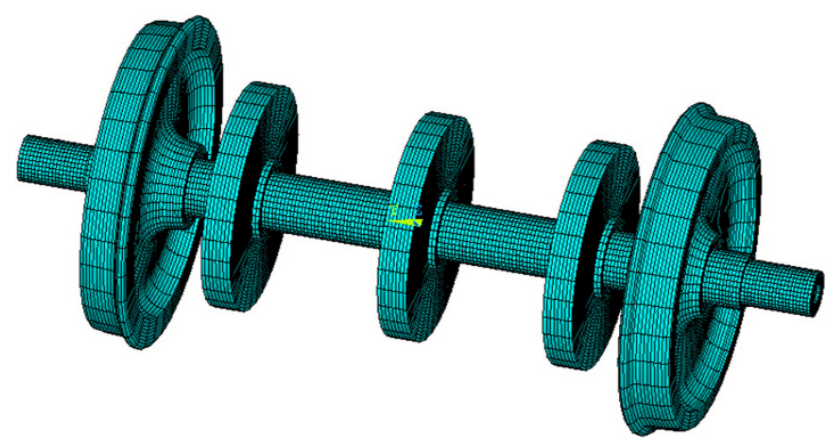

Fig. 1 Wheelset finite element model

(a)

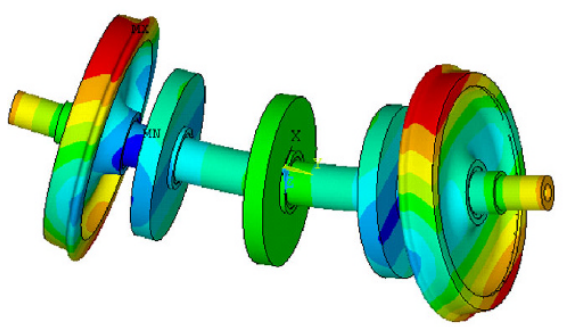

(b)

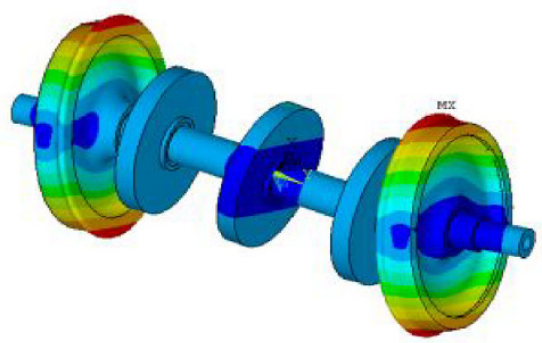

(c)

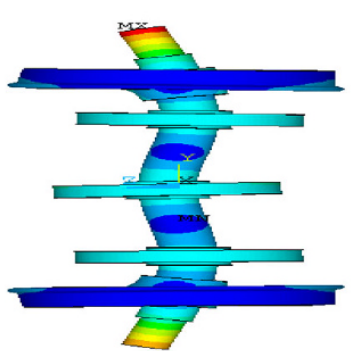

Using the Guyan reduction method and maintaining the overall shape of the structure, a freedom set with a uniform distribution was selected. Through modal analysis using the finite element model and without imposing any constraints, the first 30 modes were obtained and imported to the SIMPACK dynamic analysis software. The rigid-flexible coupling dynamic model of the vehicle system was then built. The mode shapes of the flexible wheelset are shown in Fig. 2. The flexible wheelset had many mode shapes which might affect the wear of the wheel profile, and thus the flexibility of the wheelset could not be ignored.

\subsection{Wear model}

Archard's wear model is a function of the sliding distance, normal force, and hardness of the material. The wear volume of the material worn away is proportional to the product of the sliding distance and the normal force, and (d)

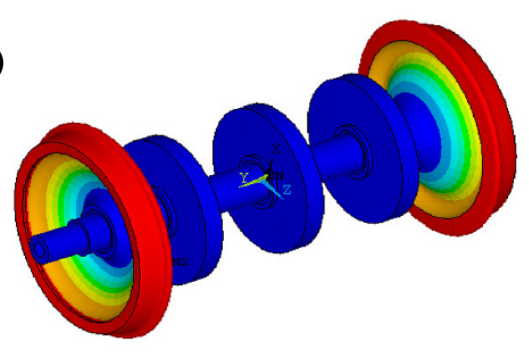

(e)

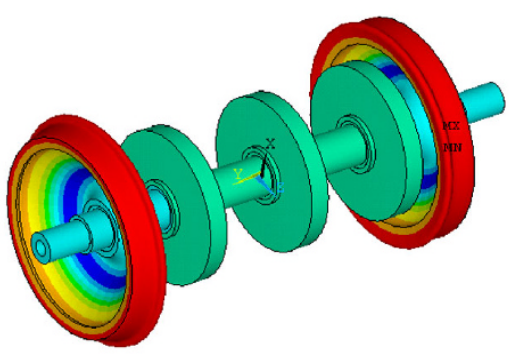

Fig. 2 Mode shapes of the flexible wheelset. a First vertical and horizontal bending modes $(77 \mathrm{~Hz})$. b Second vertical and horizontal bending modes $(133 \mathrm{~Hz})$. c Third vertical and horizontal bending modes $(575 \mathrm{~Hz})$. d First umbrella mode $(225 \mathrm{~Hz})$. e Second umbrella mode $(282 \mathrm{~Hz})$ 


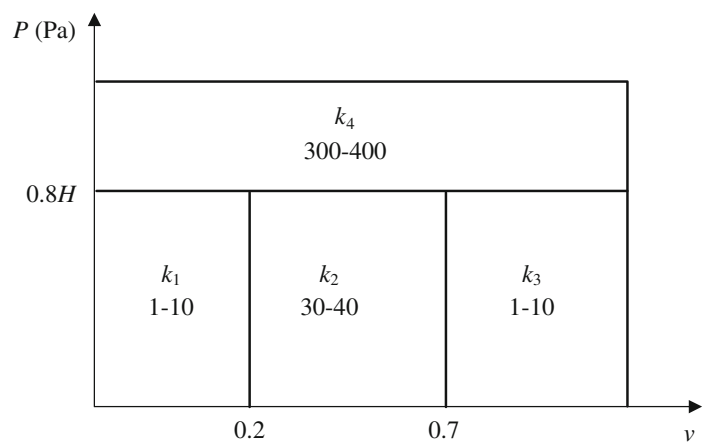

Fig. 3 Coefficient $k$

inversely proportional to the hardness of the worn material. It can be described by Eq. (2):

$V_{\text {wear }}=k \frac{N d}{H}$,

where $\boldsymbol{V}_{\text {wear }}$ is the wear volume matrix, $\boldsymbol{d}$ the sliding distance vector, $N$ the normal force matrix, $H$ is the hardness of the worn material, and $k$ is the wear coefficient.

The wear coefficient $k$ can be determined by laboratory tests or by performing extensive field measurements. It is generally a function of the sliding velocity, contact pressure, temperature, and contact environment. The wear coefficient used in the present calculation is described in the wear chart from Ref. [7]. It can be expressed in Fig. 3, in which the horizontal and vertical axes are the sliding velocity and contact pressure, respectively. This figure has been derived under dry contact conditions. The tread contact occurs in region $k_{2}$, and the flange contact occurs in the regions $k_{1}, k_{2}, k_{3}$, and $k_{4}$. In this study, $k$ is taken as the middle value in each region.

The wheel-rail contact model was set up using the simplified Kalker's algorithm Fastsim in which the wheel/ rail contact ellipse is divided into many elements. In each element, the normal contact pressure $P$, sliding distance $d$, and wear depth $z$ are expressed, respectively, by Eqs. (3)(5):

$P(x, y)=\frac{3 N}{2 \pi a b} \sqrt{1-\left(\frac{x}{a}\right)^{2}-\left(\frac{y}{b}\right)^{2}}$,

$$
\begin{aligned}
& d(x, y)=\Delta x \sqrt{(\xi-\phi y)^{2}+(\eta+\phi x)^{2}} \\
& z(x, y)=\frac{3 N k \Delta x}{2 \pi a b H} \sqrt{1-\left(\frac{x}{a}\right)^{2}-\left(\frac{y}{b}\right)^{2}} \sqrt{(\xi-\varphi y)^{2}+(\eta+\varphi x)^{2}}
\end{aligned}
$$

where $x$ denotes the longitudinal direction of the contact plane; $y$ is the transversal direction of the contact plane, and the element center point $(x, y)$ are the Cartesian coordinates of the contact patch; $\xi, \eta$, and $\phi$ denote the longitudinal creepage, lateral creepage, and spin creepage, respectively; $a$ and $b$ denotes the long axis and short axis of contact patch, respectively.

\subsection{Process of wear prediction}

The vehicle parameters, wheel-rail initial profile, mode shapes of wheelset, track random inputs, and track line conditions were taken into account in the vehicle system dynamic model. The contact patch location, size, creepage, and normal stress distribution were then calculated. Subsequently, the amount of wear for the wheel was calculated using the wear model. Finally, the wheel wear distribution was obtained, and the wheel profile was updated using the smoothing method of cubic spline interpolation. The wheel-rail contact patch was divided into $50 \times 50$ elements. The wear model predicted the change in the wear of the wheel profile through multiple iterations. The integrated simulation process for wheel wear is shown in Fig. 4.

To accelerate the wear prediction, the following hypotheses for calculating wheel wear were developed:

(1) During one integrated simulation of wear prediction, the profile of the wheel remained unchanged, and the tread was updated when the wear depth was $0.1 \mathrm{~mm}$ or the vehicle had traveled through $1,500 \mathrm{~km}$ according to previous studies $[4,8]$. On the basis of the field analysis of the measured data for a high-speed vehicle, a running distance of $1,000 \mathrm{~km}$ was taken as the step length for updating the wheel profile in this study.

(2) The vehicle structure was symmetrical, and the left and right rails on the curved track were arranged

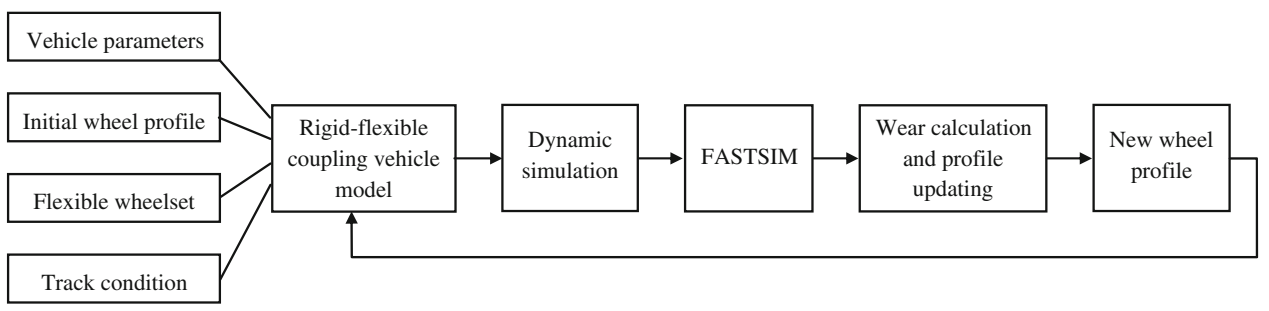

Fig. 4 Integrated simulation process 
Table 1 Typical scenarios

\begin{tabular}{llc}
\hline Track radius $(\mathrm{m})$ & Vehicle speed $(\mathrm{km} / \mathrm{h})$ & Percentage $(\%)$ \\
\hline 2,200 & 160 & 4 \\
2,800 & 180 & 4 \\
4,000 & 200 & 4 \\
Straight & 200 & 88 \\
\hline
\end{tabular}

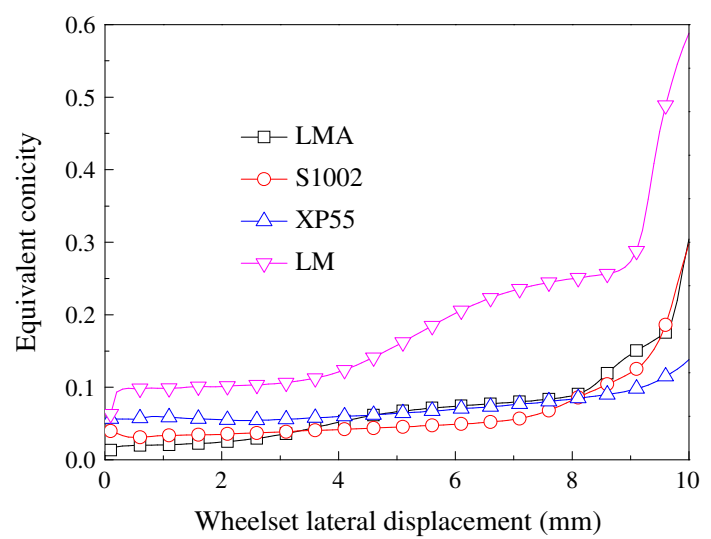

Fig. 5 Equivalent conicities for different types of wheel profiles
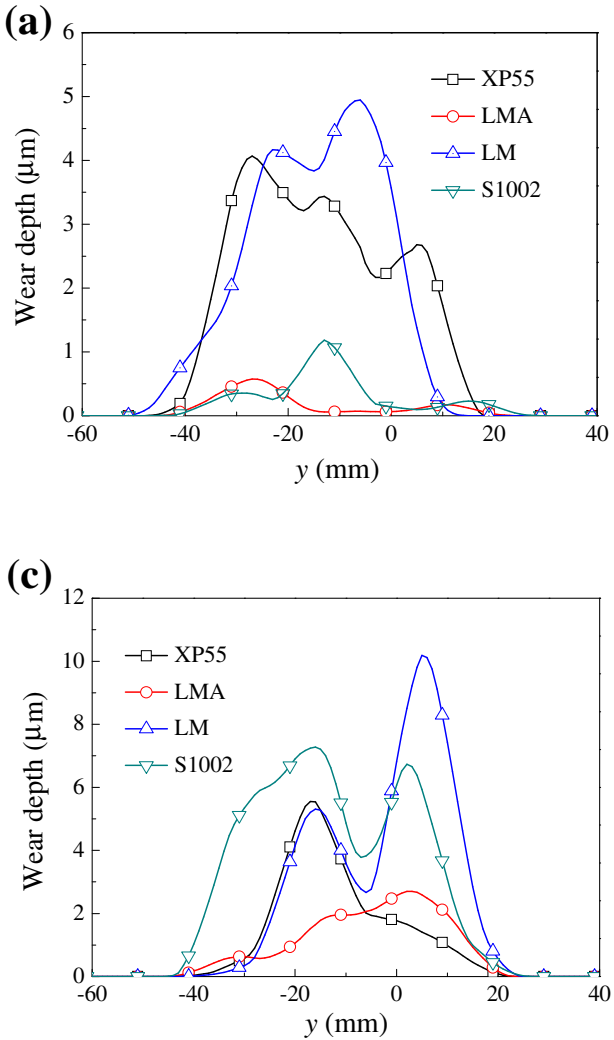

symmetrically. The vehicle always traveled forward and backward on the line, thus the wheel wear for wheelsets one and four was the same, and for wheelsets two and three was also the same.

(3) The track excitation was random, and the impact of rail wear on wheel wear was not considered.

For the wheel wear calculation, the vehicle was assumed to pass through a prescribed track consisting of three curved tracks and one straight track [20], which is shown in Table 1.

\section{Parametric analysis of wheel wear}

It is essential to acquire a better understanding on how the operation conditions influence wear evolution of the wheel profile. Therefore, the following analysis focuses on vehicle/track parameters influence of wheel profile on wear.

\subsection{Influence of wheel profile on wear}

The wear depth and distribution of four types of wheel profiles (LM, LMA, XP55, and S1002) were compared on the prescribed line conditions for the same operating mileage. Figure 5 illustrates the equivalent conicities of the

(b)

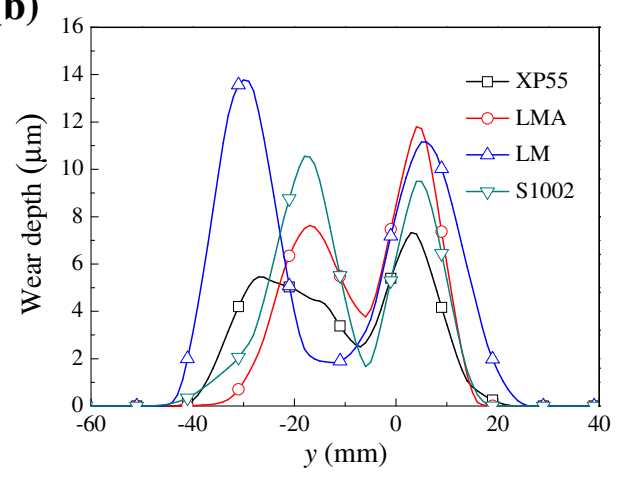

(d)

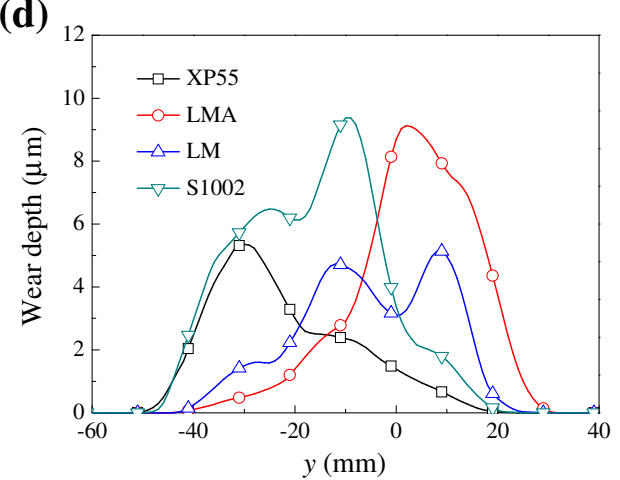

Fig. 6 Wear comparison for different types of wheel profiles. a Wear stage 1. b Wear stage 2. c Wear stage 3. d Wear stage 4 
Table 2 Wear distribution zone for different wheel profiles (mm)

\begin{tabular}{lllll}
\hline Wear stage & \multicolumn{4}{l}{ Wheel profiles } \\
\cline { 2 - 5 } & XP55 & LMA & LM & S1002 \\
\hline 1 & $-47-+18$ & $-44-+26$ & $-52-+16$ & $-46-+29$ \\
2 & $-44-+24$ & $-43-+24$ & $-45-+26$ & $-51-+24$ \\
3 & $-44-+26$ & $-45-+26$ & $-44-+25$ & $-47-+27$ \\
4 & $-51-+26$ & $-45-+32$ & $-43-+31$ & $-51-+31$ \\
\hline
\end{tabular}

four wheel profiles, and Fig. 6 shows the wear depth changes for the four wheel profiles. Figure 6 includes four wear stages for the wheel wear prediction, labeled (a), (b), (c), and (d), respectively, and each stage covered a distance of $1,000 \mathrm{~km}$. After each stage, the wheel profile was updated to enable the calculations for the next stage. In the figures, the abscissa $y$ is the horizontal axis of the wheel profile, and the origin is at the wheel nominal rolling circle position.

As known, the wear depth initially increased rapidly and then slowed with the increase in running mileage, and the wear range slowly broadened.

Table 2 shows the distribution of different types of wheel profiles for the four wear stages. In stage 1, because the type LM profile had the largest equivalent conicity, the wheel wear was close to the flange; the $\mathrm{S} 1002$ profile had
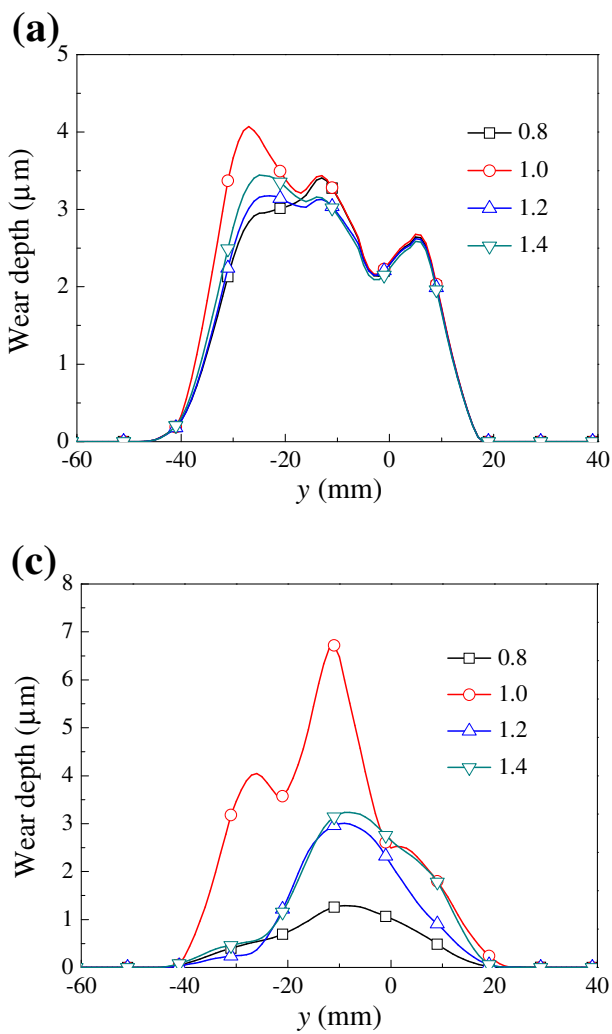

the smallest equivalent conicity, and the wheel wear was near the outside of the wheel. For the later wear stages, the wear volume for LM was the greatest and the wear ranges the widest; and the wear volume for XP55 the smallest. Therefore, the selection of an appropriate wheel profile and equivalent conicity is very important for the actual wheel wear. If the equivalent conicity was too large, then the large contact angle would cause the spin creep to increase. At the same time, the wheel rail contact point was closer to the flange, and the wheel wear would be more serious. On the other hand, if the difference in the rolling radii between the left and right wheels increased, then the deviation from the center position of the wheelset caused greater longitudinal creep and increased the wear depth. If the equivalent conicity was too small, then the lateral motion of the wheelset would be greater to widen the wear range because of the weak centering ability. Therefore, a too large or too small equivalent conicity will intensify the wheel wear.

\subsection{Influence of primary vertical stiffness on wear}

To compare the influence of primary vertical stiffness on the wear depth and range, the primary vertical stiffness with values $0.8,1.0,1.2$, and $1.4 \mathrm{MN} / \mathrm{m}$ was adopted for the calculation. Figure 7 shows that the primary vertical stiffness has little influence on the wear range. In the wear
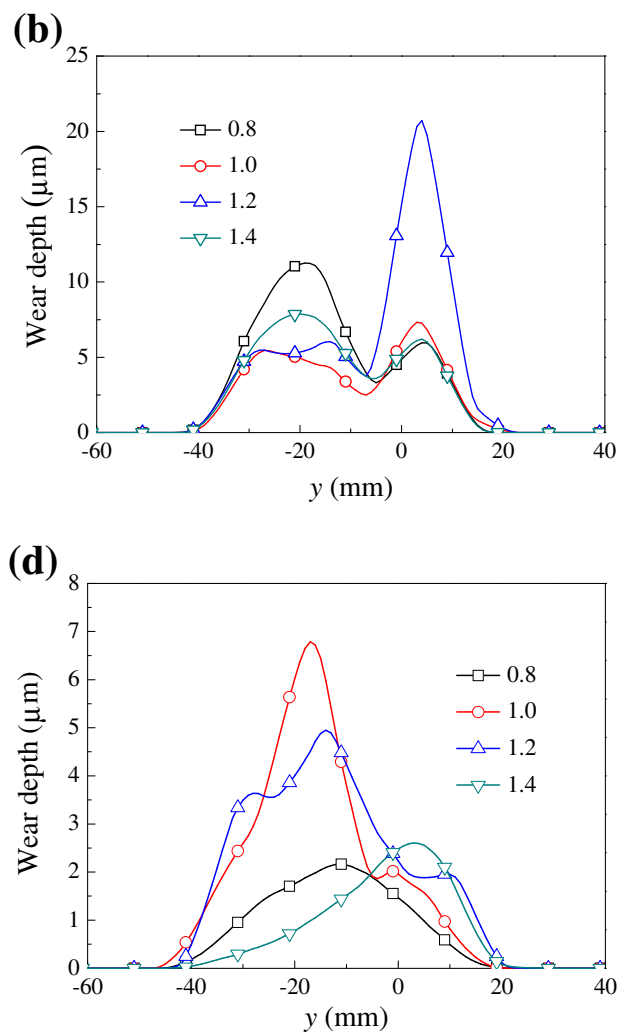

Fig. 7 Wear comparison for different primary vertical stiffnesses. a Wear stage 1. b Wear stage 2. c Wear stage 3. d Wear stage 4 
(a)

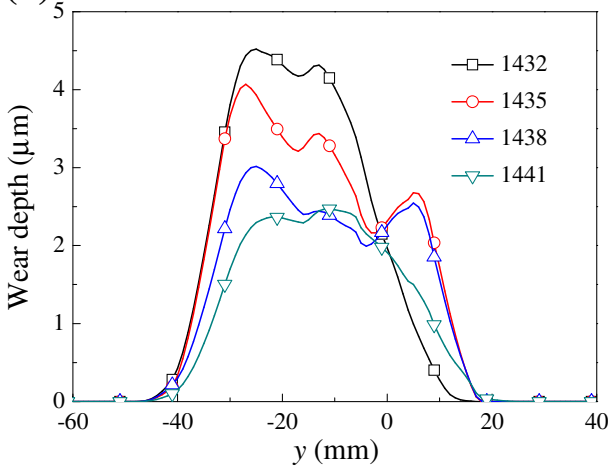

(c)

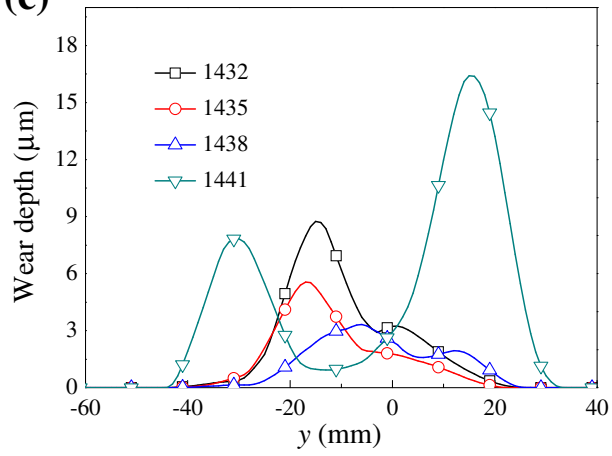

(b)

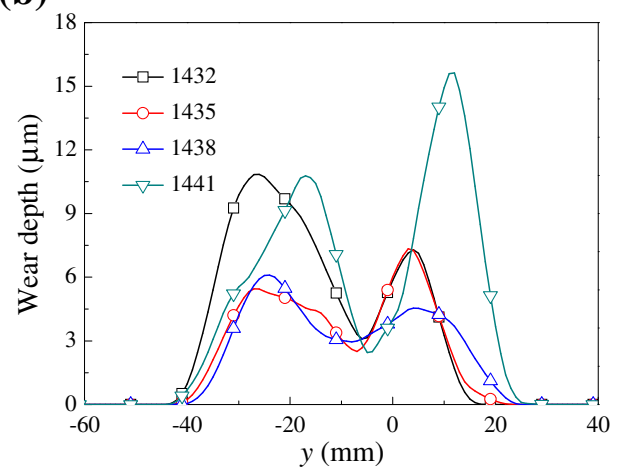

(d)

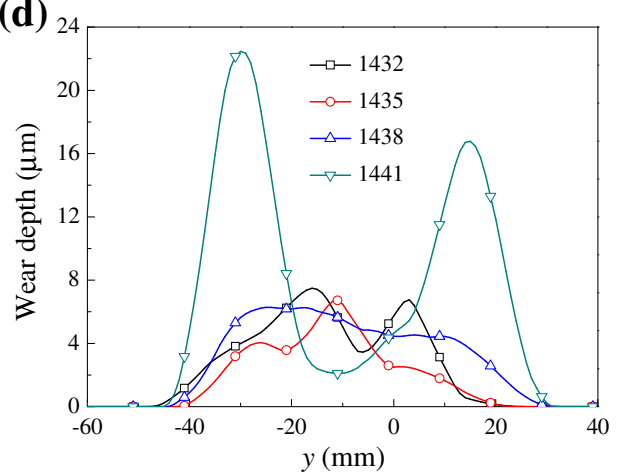

Fig. 8 Wear comparison for different track gages. a Wear stage 1. b Wear stage 2. c Wear stage 3. d Wear stage 4

(a)

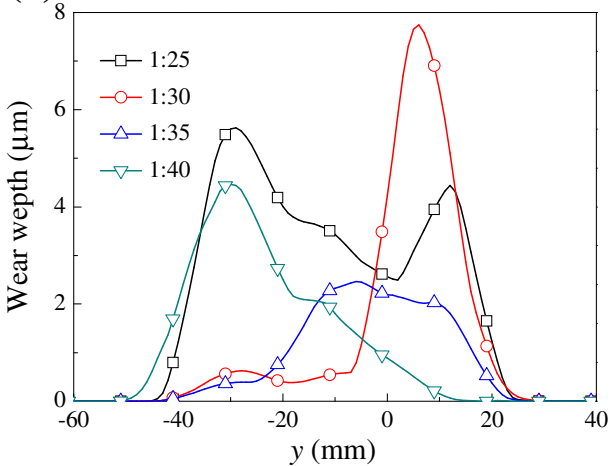

(c)

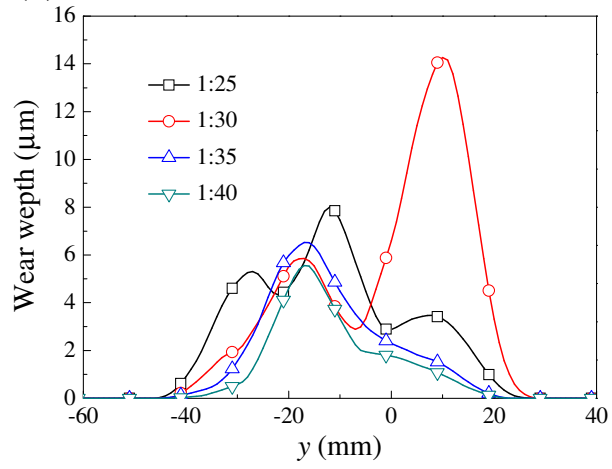

(b)

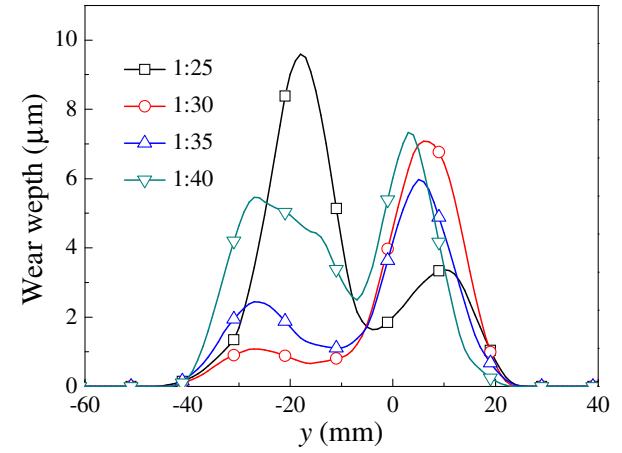

(d)

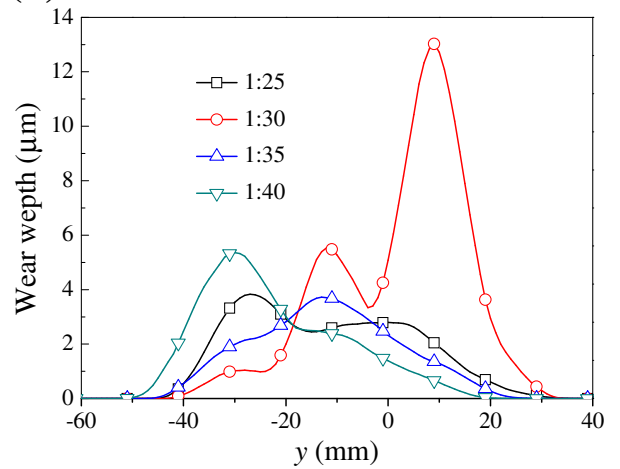

Fig. 9 Wear comparison for different rail cants. a Wear stage 1. b Wear stage 2. c Wear stage 3. d Wear stage 4 
stage 3 , the primary vertical stiffness has little effect on the wear depth; in the further wear stages, the stiffness $1.0 \mathrm{MN} / \mathrm{m}$ will cause greater wear than the others, and the stiffness $0.8 \mathrm{MN} / \mathrm{m}$ has the least wear. With the increasing of running mileage, the wear depths increase rapidly in the early stages and slowly in the later stages.

\subsection{Influence of track gage on wear}

The computed track gages were $1,432,1,435,1,438$, and $1,441 \mathrm{~mm}$, and their influences on the wear depth and distribution of the wheel profiles were compared in Fig. 8. We can see that wear depth reduces and wear range gradually moves away from the flange with the increase in track gage in the first stage. In the later stages, track gages 1,435 and $1,438 \mathrm{~mm}$ have the least wheel wear depth. Thus, slightly widening the track gage is advantageous for reducing wheel wear.

\subsection{Influence of rail cant on wear}

Rail cants of 1:25, 1:30, 1:35, and 1:40 were selected for the wheel wear calculation. As shown in Fig. 9, the wear depth was small when the rail cant angles were 1:35 and 1:40, and the wear distribution was near the flange. Thus, the rail cant should be between 1:35 to 1:40 to reduce wheel wear.

\section{Conclusions}

To study wheel profile wear, a vehicle dynamic model and a wheel profile wear model were established. The influence of wheel profile, primary vertical stiffness, track gage, and rail cants on wheel profile wear was investigated through numerical simulations, and the following conclusions were reached:

(1) The shape of the wheel profile has a significant influence on wheel wear depth and range. Among the four types of wheel profiles, the type XP55 wheel had the smallest cumulative wear depth, and LM had the largest wear. To reduce the wear of the wheel profile, an appropriate wheel equivalent conicity needs to be designed, and must not be too large or too small.

(2) Using a small primary vertical stiffness can have a better dynamic performance and reduce wheel wear.

(3) The track gage should be between 1,435 and $1,438 \mathrm{~mm}$, a too large or too small gage will aggravate the wheel wear, and rail cant should be between $1: 35$ to $1: 40$.

Acknowledgments The authors would like to acknowledge the support of the National Natural Science Foundation of China (No. 51005189) and the National Key Technology R\&D Program of China (2009BAG12A01).
Open Access This article is distributed under the terms of the Creative Commons Attribution License which permits any use, distribution, and reproduction in any medium, provided the original author(s) and the source are credited.

\section{References}

1. Jin XS, Liu QY (2004) Tribology of wheel and rail. China Railway Press, Beijing

2. Zhou L, Shen ZY (2011) Progress in high-speed train technology around the world. J Mod Transp 19(1):1-6

3. Braghin F (2006) A mathematical model to predict railway wheel profile evolution due to wear. Wear 261:1253-1264

4. Li X, Jin XS, Wen ZF et al (2011) A new integrated model to predict wheel profile evolution due to wear. Wear 271:227-237

5. Fries RH, Dávila CG (1988) Analytical methods for wheel and rail wear prediction. Proceedings 10th IAVSD Symposium, Swets and Zeitlinger: $112-125$

6. Pearce TG, Sherratt ND (1991) Prediction of wheel profile wear. Wear 144:343-351

7. Li ZL, Kalker JJ, Wiersma PK et al. (1998) Non-Herztian wheelrail wear simulation in vehicle dynamical systems. Proceedings 4th International Conference on Railway Bogies and Running Gears. Budapest: 187-196

8. Jendel T (2002) Prediction of wheel profile wear-comparisons with field measurements. Wear 253:89-99

9. Luo R, Zeng J, Wu PB et al (2009) The influence of high speed trains between wheel and rail parameter on wheel profile wear. Traffic Transp Eng 9(6):47-63

10. Ignesti M, Innocenti A, Marini L, Meli E, Rindi A (2013) Development of a wear model for the wheel profile optimisation on railway vehicles. Veh Syst Dyn 51(9):1363-1402

11. Pombo J, Ambrosio J, Pereira M, Verardi R, Ariaudo C, Kuka N (2011) Influence of track conditions and wheel wear state on the loads impose on the infrastructure by railway vehicles. Comput Struct 89:1882-1894

12. Agostinacchio M, Ciampa D, Diomedi M, Olita S (2013) Parametrical analysis of the railways dynamic response at high speed moving loads. J Mod Transp 21(3):169-181

13. Fergusson SN, Frohling RD, Klopper H (2008) Minimising wheel wear by optimising the primary suspension stiffness and centre plate friction of self-steering bogies. Veh Syst Dyn 46(1):457-468

14. Li X, Wen ZF, Zhang J, Jin XS (2009) Effect of rail cant on wheel/rail rolling contact behavior. J Mech Strength 31(3):475-480

15. Wang WJ, Guo J, Liu QY (2010) Effects of track parameters on rolling contact behavior of wheel-rail. J Sichuan Univ (Eng Sci Ed). 42(6):213-218, 226

16. Chen P, Gao L, Hao JF (2007) Simulation study on parameters influencing wheel/rail wear in railway curve. China Railw Sci 28(5):19-23

17. Chang CY, Wang CG, Jin Y (2008) Numerical analysis of wheel/ rail wear based on 3D dynamic finite. China Railw Sci 29(4):89-95

18. Baeza L, Vila P, Xie G, Simon Iwnicki D (2011) Prediction of rail corrugation using a rotating flexible wheelset coupled with a flexible track model and an on-Hertzian/non-steady contact model. J Sound Vib 330:4493-4507

19. Telliskivi $\mathrm{T}$ (2003) Wheel-rail interaction analysis. Doctoral Thesis, Department of Machine Design, KTH

20. He HW (2003) Speed up technique of $200 \mathrm{Km} / \mathrm{h}$ on Chinese previous railway. China Railway Publishing House, Beijin 